Оригинальная статья

Институт социологии Федерального научно-исследовательского социологического центра Российской академии наук ул. Кржижановского, д. 24/35, корп. 5, Москва, 117218, Россия r_lenkov@mail.ru

Аннотация. В статье актуализируется проблема целеполагания социокультурной модернизации регионов Российской Федерации в плане выявления её потенциала в территориальных региональных сообществах как организационных системах с разным уровнем развития, а также обоснования регуляторов для организации процесса целеполагания при выстраивании отношений заинтересованных лиц с субъектами систем управления. Рассматривается история становления понятия «цель», раскрывается практический опыт целевого управления и планирования (на примере СССР), основанный на результатах теоретических исследований по осознанию роли цели и целенаправленности в системах организационного управления. Характеризуется закономерность эквифинальности и её использование при целеобразовании на региональном уровне. В основу работы положен опыт изучения управляемости регионального развития, полученный учёными Центра социологии управления и социальных технологий Института социологии Федерального научно-исследовательского социологического центра Российской академии наук в 2015-2020 гг. Особое внимание уделено научным результатам исследования интеллигенции как латентной группы в контексте управляемости социокультурной модернизации регионов, включая развитие систем управления и роль высшего образования. В заключение специфицирован ряд оставшихся за рамками исследования проблемных вопросов для дальнейшего анализа значения интеллигенции с акцентом на «сборку» субъектности в условиях спонтанных и целерациональных изменений в саморазвивающихся сообществах.

Ключевые слова: целеполагание, закономерности целеобразования, социокультурная модернизация, регионы, высшее образование интеллигенция, субъектность, социопрогностическая концепция

Благодарности: В статье использованы материалы научного доклада Р. В. Ленькова и В. С. Богданова «К вопросу изучения интеллигенции в контексте управляемости социокультурной модернизацией» на XXI международной теоретикометодологической конференции «Интеллигенция: многообразие стилей и образов жизни», РГГУ, 1 октября 2020 г. 
Информация для цитирования: Леньков Р. В. Проблема целеполагания социокультурной модернизации российских регионов: закономерности, регуляторы, субъектность // Научный результат. Социология и управление. 2020. T. 6, № 4. C. 42-54. DOI: 10.18413/2408-9338-2020-6-4-0-3.

Original article

\author{
Roman V. Len'kov
}

\title{
The problem of targeting socio-cultural modernization of Russian re- gions: patterns, regulators, subjectivity
}

Institute of Sociology, Federal Center for Theoretical and Applied Sociology, Russian Academy of Sciences

bld. 5, 24/35, Krzhizhanovsky St., Moscow, 117218, Russia

r_lenkov@mail.ru

\begin{abstract}
The article actualizes the problem of targeting socio-cultural modernization of the regions of the Russian Federation in terms of identifying its potential in territorial regional communities as organizational systems with different levels of development, as well as justifying regulators for organizing the goal-setting process when building relationships between stakeholders and subjects of management systems. The history of the formation of the concept of "purpose" is considered, the practical experience of target management and planning (on the example of the USSR), based on the results of theoretical research on the awareness of the role of purpose and targeting in the systems of organizational management is revealed. The regularity of equifinality and its use in targeting at the regional level is characterized. The work is based on the experience of studying the manageability of regional development, obtained by scientists from the Center for Sociology of Management and Social Technologies of the Institute of Sociology of the Federal Center for Theoretical and Applied Sociology of the Russian Academy of Sciences in 2015-2020. Particular attention is paid to the scientific results of the content analysis of the intelligentsia as a latent group in the context of the manageability of the socio-cultural modernization of regions, including the development of management systems and the role of higher education. In conclusion, a number of problematic issues that have remained outside the scope of the study are specified for further analysis of the significance of the modern intelligentsia, with an emphasis on the "assembly" of subjectivity in the context of spontaneous and goal-rational changes in selfdeveloping communities.
\end{abstract}

Keywords: goal setting, patterns of goal formation, sociocultural modernization, regions, higher education, intelligentsia, subjectivity, socio-predictive concept

Acknowledgments: The article uses the materials of the scientific report of R. V. Lenkov, V. S. Bogdanov "On the issue of studying the intelligentsia in the context of the manageability of sociocultural modernization" at the XXI International Theoretical and Methodological Conference "Intellectuals: Diversity of Styles and Lifestyles", Russian State University for the Humanities, October 1, 2020.

Information for citation: Len'kov, R. V. (2020), "The problem of targeting sociocultural modernization of Russian regions: patterns, regulators, subjectivity", Research 
Result. Sociology and management, 6 (4), 42-54, DOI: 10.18413/2408-9338-2020-6-4$0-3$.

Введение (Introduction). Актуальность проблемы. Центром социологии управления и социальных технологий Института социологии ФНИСЦ РАН (далее ЦСУиСТ ИС РАН) в 2015-2021 гг. реализуется лонгитюдный проект, поддержанный грантом РНФ (Россия: реформирование..., 2017). Его цуель - изучение механизмов регулирования и повышения управляемости отношений между государством и населением в решении проблем социокультурной модернизации регионов (как ответа на вызовы и угрозы современного мира). Результаты проекта диагностировали не только образование социально-статистических групп на основе экспертной оценки респондентами работы звеньев властно-управленческой вертикали, но и их реальное участие в латентном группообразовании в регионах при реализации комплекса социальных и культурных преобразований с учётом изменений институциональной среды. Однако интересы отдельных групп населения на уровне региональных образований, особенно в системе местного самоуправления, слабо учитываются властно-управленческой вертикалью, в результате чего значительные группы граждан оказались в состоянии социального отчуждения от декларируемой государством политики.

Согласно процессу социального группообразования, человек выступает не просто как объект в организационной системе не зависимых от него производственных, политических и иных отношений, но и как субъект, стремящийся найти, понять, объяснить и изменить свою роль в обществе. При этом «наибольшее дифференцирующее влияние на состояние параметров субъектности оказывают возрастной и профессиональный факторы; а образовательный ресурс повышает уровень самостоятельности, даёт сво- боду выбора, способность принимать решения и нести ответственность» (Касьянова, 2007: 20-21).

Нам видится логичным продолжение исследований социально-структурного группообразования в российском обществе, которые должны быть дополнены сведениями о трансформации регионального пространства, где синхронно с происходящими в мире и стране событиями реализуются практики социального взаимодействия. Изучение механизмов социального группообразования требует актуализации проблемы изменений в отношениях между населением («гражданским обществом») и властью в условиях исторически обусловленного обострения внешних и внутренних вызовов, включая вопросы о характере диспозиций граждан как социальных агентов и об их участии в оценке работы звеньев властноуправленческой вертикали.

Сегодня можно утверждать, что геополитическая нестабильность, глобальные и национальные потрясения, турбулентность и экономические кризисы в обществе XXI века порождают новые явления, актуализируя их востребованность без рациональнопознавательного осознания последствий в виде прекариата, диджитализации, кидалт («взрослых детей»), дауншифтинга и т.п. На таком фоне возникают вопросы: Кто и каким образом должен и может осуществлять социальные изменения в современном обществе, когда основная платформа воспроизводства профессиональных субъектов для этих целей пробуксовывает, а компетенции начинают доминировать над знанием? И сложно не согласиться, что компетенции сегодня скорее инструмент демонстрации лояльности образовательных организаций высшего образования институциональным требованиям, чем реальная оценка качества 
самого образования (Щербина, Попова, 2020: 631).

Логично встаёт вопрос о постановке проблемы влияния образования на механизмы обеспечения высокого уровня солидарности общества в решении проблем социокультурной модернизации регионов, а также развития социопрогностической конщеециии с упором на активное начало элементов территориально-пространственных систем (регионов) и обратную связь. Важными компонентами концепции выступают целеполагание и организация процессов коллективного формирования целей-побуждений к действию. Актуальным становится поиск путей воспроизводства и поддержания потенциально «продуктивных» социальных групп, готовых к результативной, интеллектуальной «сборке» субъектности, а также формирования регулятивных механизмов, способных обеспечить не оппозиционный социально-ориентированный характер целеполагания в отношениях общества и власти.

Методология и методы (Methodology and methods). Теоретико-методологическим основанием исследования выступает парадигма открытой системы, выдвинутая Л. фон Берталанфи ещё в 30-е гг. XX века, позже получившая развитие в трудах Н. Т. Абрамовой, В. Г. Афанасьева, В. Н. Волковой, М. Г. Макарова, Л. А. Растригина, В. Н. Сагатовского, В. С. Тюхтина, Ю. И. Черняка; Р. Акоффа, Ф. Эмери и др.

Согласно этой, широко известной парадигме в системах организационного управления любого уровня иерархии (в нашем случае - это региональный уровень) общими принциипами или закономерностями иелеобразования являются: целостность (автономность), иерархическая упорядоченность и эквифинальность (итоговое, финальное состояние). Кроме этих, базовых закономерностей указанная парадигма определяет закономерности интегративности, коммуникативности и историчности.
Сформулированные учёными выводы важны в осознании для организации управления категории «цель-побуждения к действию», что позволяет переосмыслить закономерности целеобразования, в том числе с учётом взаимодействия внешних и внутренних факторов.

Сегодня актуален акцент на внутренних началах организационных систем, поскольку они активны и приводят к проявлению у социальных объектов особых свойств. Назовём их: неповторимость и непредсказуемость, неустойчивость поведения и подвижность параметров, а также способность к изменению своей структуры и адаптации в быстро меняющихся условиях (включая управляющие воздействия) и, наконец, стремление вырабатывать варианты поведения через целеобразование. Это объясняется наличием у таких систем субъектности людей, которые способны противостоять энтропийным (разрушающим) тенденциям и создавать негэнтропийные (Л. фон Берталанфи, Дж. Ванн Гиг, И. Р. Пригожин).

Под иелеполаганием в исследовании понимается процесс «установления идеально предположенного результата созидательной деятельности человека или группы людей». Это исходная, первая из пяти известных форм конкретизации предуказательной функции научного предвидения в управлении, за которой следуют: проектирование, планирование, программирование и текущие управленческие решения (Леньков, 2020). Такое понимание основывается на теории научного предвидения, разработанной в 50-е гг. XX века А. М. Гендиным, И. В. Бестужевым-Ладой и др., позже адаптированной Т. М. Дридзе, Б. С. Сивириновым, В. Н. Стегнием, Ж. Т. Тощенко, О. А. Уржа, В. И. Франчуком и др. к социологии и социологии управления.

В работе применяется подход, последовательно развиваемый исследовательским коллективом под руководством Н. И Лапи- 
на, который предлагает рассматривать пространственно-территориальную панораму модернизационных процессов (разный уровень развития). Для нас актуально гуманистическое основание модернизации, представляющее комплекс социальных и культурных преобразований (соииокультурная модернизаичи).

Управляемость модернизации связывается в исследовании с обеспечением сбалансированности взаимодействия между основными её компонентами: техникотехнологической, социо-экономической, социокультурной и институциональнорегулятивной. В роли институцииональнорегулятивной компоненты выступает совокупность регулирующих институтов, одним из которых является высшее образование.

Теоретическим и эмпирическим концептом исследования выступает термин «интеллигенция». Это проблемный (в осмыслении и понимании) концепт. Учёныегуманитарии определяют его по-разному: от «класса производителей символических благ» (П. Бурдье) до «терпимого отношения к миру и к людям» (Д. С. Лихачёв). В контексте настоящей работы под интеллигенцией понимается социальная группа людей, осознанно отвечающих за рост и сочиальное развитие, конструктивные подходы к организации и самоорганизации общества. Это группа, способная запустить механизм самодостраивания (интеллектуальной «сборки») и взять на себя интегрирующую функцию выработки стратегического вектора социокультурной модернизации.

Целью исследования выступает анализ потенциала целеполагания социокультурной модернизации в региональных сообществах (как сложных системах с разным уровнем развития) на основе учёта регуляторов процесса её организации в отношениях заинтересованных лиц с субъектами систем управления. Специальная задача - изучение современной интеллигенции как латентной группы в контексте управляемости социокультурной модернизации регионов.

Информационной базой являются результаты исследования управляемости регионального развития, полученные учёными ЦСУиСТ ИС РАН в 2015-2020 гг., в том числе полученные автором при исследовании высшего образования как институционально-регулятивного ресурса управления социокультурной модернизацией регионов, оценке поддержки населением с высшим образованием политики модернизации в 4-х пилотных регионах с различным уровнем социокультурной модернизации.

При проведении исследования использованы общие положения теории систем и системного анализа, методы ретроспекциии (при анализе советского опыта целевого управления и планирования) и контентанализа (при изучении интеллигенции как латентной группы), обобщение и систематизация информации, а также результаты научных публикаций учёных в области социальной философии, психологии, кибернетики, социологии управления и теории организации.

Научные результаты и дискуссия (Research results and discussion).

Смысл «цели» в управляемости социокультурной модернизации.

Процессуальность целеобразования и целеполагания социокультурной модернизации регионов весьма сложное явление.

Эта сложность обусловлена непрерывным и последовательным развитием представлений о цели в философии, социологии и теории познания. Так, анализ смысла цели и связанных с ней категорий целесообразности и целенаправленности демонстрирует, что в зависимости от стадии познания объекта (в нашем случае - сочиокультурной модернизации) в «цель» вкладываются разные оттенки. Они вписаны в пределах условной «шкалы»: от идеальных устремлений («цели, достижение которых невозможно, но к 
которым можно приближаться», Акофф, 1972) к материальному воплощению: результаты, достижимые в некотором интервале времени или конечный продукт деятельности. Фактически в смысле цели заключено противоречие в том, что она должна быть «опережающей идеей», побуждающей к действию, и вместе с тем - материальным её воплощением.

Часто для отражения указанного противоречия дают следующее определение: «цель - это заранее мыслимый результат сознательной деятельности человека или группь людей» («заранее мыслимый», но всё же «результат» как воплощение замысла; кроме того, подчёркивается, что цель связана с «сознательной деятельностью»). Такое диалектическое понимание цели крайне важно при организации текущих управленческих решений. Но в реальных обстоятельствах, как отмечает В. Н. Волкова, надо объяснить, в каком смысловом контексте на конкретном этапе рассмотрения объекта оно используется и что должно быть отражено в её формулировке: идеальные устремления, позволяющие увидеть перспективы, или реальные возможности, обеспечивающие завершение очередного этапа построения ожидаемого будущего (Волкова, 1995).

Проведённый анализ смыслов цели является весомым шагом на пути к практической реализации процесса целеполагания социокультурной модернизации регионов. Также в социальной практике, с нашей точки зрения, инструментальный потенциал имеет концепциия единственности цели B. А. Чабровского, которая даёт представление о двух различных образах цели: «цеель деятельности» (актуальная, конкретная цель) и бесконечная по содержанию «цельстремление» (идеальная, потенциальная цель).

Цели в управляемости социокультурной модернизации. Этапы развития цеелево- го управления и планирования (из опьта СССР).

В истории нашей страны накоплен значительный опыт целевого управления и планирования, использующий результаты исследований по раскрытию целеустремлённости в системах организационного управления.

Идея перспективного планирования возникла в связи с реализацией государственного плана электрификации Советской России после Октябрьской революции 1917 года. Позднее она трансформировалась в директивное планирование «от достигнутого» и разработку пятилетних планов без каких-либо прогнозных оценок структурных сдвигов в организации управления различными отраслями народного хозяйства.

В 1960-е гг. была предложена концепцุия программно-цеелевого планирования $u$ управления, её следствием явилось включение категории «цель» в систему экономических и управленческих решений на самых высших уровнях руководства экономикой и страной.

Концеепциия роли цуели в управлении как побуждения $\kappa$ деятельности, получившая развитие в 1970-е гг., позволила осознать необходимость замены жёсткого планирования на комплексное прогнозирование и программирование развития научнотехнического прогресса и его социальноэкономических последствий на 20 лет, а также Основных направлений экономического и социального развития страны на 1015 лет.

Эти нововведения фактически реализовали социальную практику закономерности целеобразования, ставящей цель в зависимость от времени и увязывающей её изменение по мере познания и развития системь.

Также была осознана полезность привлечения к прочессам целеобразования (прогнозированию и перспективному планирова- 
нию) широкой научной общественности руководителей и специалистов, которые участвовали в соответствующих комиссиях (при Академии наук, Госплане, Государственном Комитете по науке и технике Coвета Министров), обосновывая прогнозы и основные направления развития СССР.

Это решение частично реализовывало условия реализации закономерности целеобразования, осуществляющей учёт внутренних потребностей, мотивов и программ посредством представителей различных слоёв населения, включаемых в состав комиссий.

Работа членов комиссий состояла в сборе письменно обоснованных предложений («сценариев») и участии в совместных заседаниях. Они обобщали и готовили для Совета Министров СССР документы по Основным направлениям экономического и социального развития страны на 10-15 лет, а также пятилетних планов развития народного хозяйства. К работам такого масштаба привлекалось не только правительство, но и большое число наиболее компетентных членов общества - учёных из академий наук, руководителей и научных сотрудников из научно-исследовательских институтов, профессоров и преподавателей из вузов.

Проект Основных направлений широко публиковался в печатных средствах массовой информации, и любой гражданин имел право внести свои коррективы и новые предложения. Аналогичная работа проводилась и на уровне регионов и отраслей народного хозяйства.

Таким образом, были созданы условия для участия в целеобразовании всех заинтересованных лиц. Другое дело, что на практике граждане редко пользовались имеющимися правами при излишне централизованной системе мега-планирования; кроме того, обработка полученных предложений с использованием принятия решений по большинству однотипных предложений не позволяли вынести противоречивые мнения для обсуждения на уровень государственных и региональных органов управления.

Закономерность эквифинальности и её использование при целеобразовании на региональном уровне.

Формулирование «цели-идеала» связано с системами ценностей личности и общества, а также с уровнями цивилизационного развития территориальных региональных сообществ. Эти обстоятельства определяют желаемое будущее, характеризуемое закономерностью эквифинальности - динамическим свойством системы при переходе из начального состояния в финальное, часто имеющее предельный уровень развития.

При рассмотрении регионального уровня развития социума и его образований необходимо опереться на исследования В. И. Вернадского и его последователей. В этих трудах нет упоминаний об эквифинальности, но они способны помочь ответить на многие нерешённые вопросы.

Развивая мировоззрение учёного, связанное с представлением о ноосфере (сфере разума), социальные философы определяют пневмосферу (духовную сферу), этасферу (сферу этики) и сферу нравственности. В частности, они дают характеристики существующему уровню бытия человечества, названному антропоиентризмом (Сагатовский, 1994).

Данный уровень реализует принцип «человек - царь природы», из него развивается эгоцентризм с принципом «человек центр мироздания, повелитель», ориентирующий все ресурсы природы на службу человеку («знание - сила»). Между природой и людьми возникают противоречия и конфликты, имеющие крайние формы проявления в виде тоталитаризма, мировых войн, экологических проблем, истощения природных ресурсов и, как следствие - затруднений и угроз гибели человечества (до- 
клады Римского клуба; Леньков, 2020: 17-22).

Конечно, проблема согласования глобальных и локальных критериев трудно разрешима, но в сложных системах при принятии решений возможно использование методов активизации интуиции и опыта руководителей и специалистов как носителей систем ценностей и традиций. Они могут и должны пытаться разрешить противоречия с учётом здравого смысла и необходимости сохранения территориальных общностей. В этом большую роль играют рассмотренные выше исследования, а также необходимость использования полученных выводов при образовании «цели-идеала», не абсолютизирующего права и свободы человека, а обязывающего его к сотворчеству с другими, компромиссам, поиску своей социальной ниши.

Применительно к региональному сообществу выделим такие иерархически упорядоченные пространства развития человека и сообщества, как ситуативное пространство смыслов, сочиальное пространство, пространство культуры и пространство «вечныхх смисслов.

Капиталистическое общество, основанное на философии Т. Гоббса, индивидуализме и конкуренции, соответствует первому пространству, в котором каждый индивид или общность (регион) рассматривают другую общность как средство для достижения своих целей.

Р. Акофф и Ф. Эмери, мечтая об общине, стремящейся к идеалу, предлагали принципы, соответствующие второму пространству, в котором индивид или общность стремятся ставить социально значимые цели, при этом цели сообщества часто признаются выше индивидуальных, возможно даже подавление локальных подцелей ради достижения общей цели.

Но, как показывает практика, цели региона формулируются либо только с учётом развития экономики (на материальнотехническом уровне), либо, ориентируясь на человека, ставятся конкретные цели по решению внутренних вызовов и угроз социально-экономического характера, например, в части повышения уровня и условий жизни. Примечательно, что уровень поддержки эффективности работы регионального уровня властно-управленческой вертикали группой высокообразованного населения регионов с разным состоянием модернизации, в частности Московской и Белгородской областей, республик Башкортостан и Калмыкия, имеет умеренную ориентацию: треть выступает «за», треть - «против» и более трети (около 40\%) воздерживаются (Леньков, 2018: 208).

Мы полагаем, что принципиально важно при формулировании целей региона, наряду с целью «улучшения качества жизни местного сообщества» ставить цель «увеличения его вклада в развитие страны» как более общей системы, от состояния которой в силу закономерности целостности зависит качество жизни и региональное развитие. При этом высшее образование и высокообразованное население способны оказать влияние на механизм обеспечения высокого уровня солидарности общества в решении проблем модернизации регионов, на рост социальной и гражданской субъектности.

Современный вектор и смысл стратегии и тактики построения сетевого социального пространства актуализируют процесс целеполагания через поэтапную реализацию социокультурной модернизации регионов Российской Федерации с разным уровнем социокультурной модернизации «сверху» (органы власти и управления) и «снизу» (население) (Тихонов, 2018: 72-83). Так уж сложилось, что в нашей стране одна реформа, часто незаконченная, сменяет другую, но не даются оценки достижения показателей реформирования. Отсюда остро встаёт вопрос о социальной полезности (социальных эффектах) от декларируемых про- 
цессов в ходе реформ государственных институтов и гражданского общества, что напрямую связано с необходимостью структурных изменений сферы государственного управления и регулирования, а также усиления роли высшего образования как регулятора социокультурной модернизации за счёт грамотного использования потенциала цифровизации.

С нашей точки зрения, актуализация вопроса форм и степени целеполагания процессов социального группообразования в регионах требует специального изучения современной интеллигенции как латентной группы в рамках управляемости социокультурной модернизацией регионов. При этом крайне важен акцент не столько на функциональные особенности воспроизводства социально и культурно значимых для общества символических образцов этим социальным слоем, сколько на его способности к саморефлексии и «сборке» активной субъектности в условиях спонтанных и преднамеренных (целерациональных) изменений.

С целью онлайн-дискуссии в социальной сети Facebook в общедоступных группах «Проблемы образования и науки» (4731 участник) и «Вузовское сообщество Москвы» (608 участников) в январе 2020 г. была представлена статья «Проблемы «сборки» будущей российской интеллигенциии как потенциила социокультурной модернизации: социолого-управленческий дискурс», см. Том 5, № 4, 2019 настоящего журнала (Леньков, Богданов, 2019). Указанные группы занимаются выявлением, профессиональным анализом и поиском путей решения проблем образования и науки, обсуждением критики реформ, законов, требований в высшей школе; их целевой аудиторией является гуманитарная и техническая интеллигенция, в частности, профессора и преподаватели вузов.

Комментарии участников дискуссии обобщены и систематизированы по призна- кам интересности предложений и выводов, актуальности поднимаемых вопросов.

Отдельные выводы и рекомендации:

«Совершенно не факт, что именно социогуманитарные дисциплины в их нынешнем состоянии (состоянии нытья ненужных, обиженных, невидимых) реально могут чтото сделать в рассматриваемой области. Сейчас скорее можно поставить на машинное обучение, технологии Big-Data или вебсервис GitHub»;

«У каждого философа и социолога должна быть своя (и не одна!) модель машинного обучения, живой профиль на GitHub. У каждого социального проектировщика должен быть ультра-микросоциальный проект, реализованный на уровне ближайших друзей, семьи и коллег»;

«Прекратить накладывать красивые синергетические законы, истолкованные из естественных наук, на общество, и начать проверять их действие в минимальных ячейках (необязательно политических, но компактных), без большой борьбы масштабных концепций, напрасно расходующих интеллектуальные ресурсы и время»;

«Сейчас любой философской или социологической концепции категорически нужен результат, пусть малый, но ощутимый и осязаемый, а главное - масштабируемый. Этим надо заниматься»;

«Спасение интеллигенции - кто бы это ни был - в руках самой интеллигенции!».

Среди прочих сформулированы следуюшие актуальные вопросы:

«Почему гуманитарии всё время стараются мимикрировать под естественные науки? Зачем эти «социокультурные интеллигентские аттракторы»? Неужели вам недостаточно своей терминологии?»;

«Почему социально-философские исследования, посвящённые интеллигенции, не находят никакого (ноль, зеро) отклика у коллег из смежных дисциплин? У тех же со- 
циологов, психологов, управленцев и историков?»;

«Как социологу-исследователю сделать какую-то «группу прорыва», самому изучить свой же контекст, самому проверить то, что написал, самому запустить «самоорганизующиеся» процессы?»;

«Почему именно производители символического капитала должны быть потенциалом? Зачем нам нужна их «сборка»?»;

«Почему вузовская интеллигенция смиренно принимает такие ухудшения условий труда, как практика годичного договора, перевод на неполную ставку, засилье плохо образованных администраторов в учёных советах, ликвидацию факультетов и кафедр, отсутствие выборности ректоров, деканов, заведующих кафедрами, требование выполнять работу, которая не оплачивается, требование переписывания РПД, ФОС и прочий вал бумаг? Почему нет никаких попыток противостояния? Никаких попыток объединения?».

Обобщая результаты онлайндискуссии, акцентируем внимание на ключевой, с нашей точки зрения, проблеме изучения современной интеллигенции как латентной группы в контексте управляемости социокультурной модернизации регионов.

Говоря о современной социальноэкономической ситуации в России и зарубежных странах, ряд учёных утверждает, что прежняя социально-классовая структура перестала существовать, канула в Лету. Такие традиционные понятия, как рабочий класс, крестьянство, интеллигенция - приобрели весьма размытый характер, распались на многочисленные фрагменты, которые не позволяют говорить о них как о каком-то мало-мальски однозначном единстве (Тощенко, 2020). Такая точка зрения интересна, но, с нашей точки зрения, не в полном объёме раскрывает суть социального явления.
Сегодня изменения социальной структуры российского общества, турбулентность и сетевые взаимодействия выхолащивают признанные контуры понимания интеллигенции как социальной группы. Они трансформируют её функции и расщепляют на латентные формы организации и самоорганизации, требующие интерпретации с позиции новых подходов к «сборке» субъектности в системе отношений гражданского общества и властно-управленческих структур в территориальных региональных сообществах.

Заключение (Conclusions). Авторская позиция. Рассмотрение заявленной в названии статьи проблемы целеполагания выводит на общую проблематику совершенствования социального механизма управляемости социокультурной модернизации регионов в сетевом социальном пространстве регионов Российской Федерации с разным уровнем развития. Такой механизм требует выстраивания на основе «умного управления», образовывающийся при разработке социально-ориентированных программ деятельности, обеспечивающих выявление конкретных проблем и путей их решения посредством применения знаний об объекте (процессе) и ответственности субъектов управления за разработку новых принципов управления с социально-контролируемой обратной связью с населением (Тихонов, Богданов, 2020). Непосредственным участником выступает «гражданское общество» в лице заинтересованных групп людей, включая продвинутых представителей гуманитарной и технической интеллигенции, осознающих свою цивилизационную роль в исправлении и недопущении перекосов при переходе к «умному управлению».

В ходе концептуальной проработки феномена интеллигенции как предварительного этапа последуюших эмпирических измерений и его экспликации, мы пришли к следующему важному выводу. 
В актуальных определениях интеллигенции нет социально-конструктивного начала, которое закрепляло бы за данной социальной группой функцию воспроизводства групп региональной субъектности, то есть «сборку» конструктивных субъектов для адекватных социокультурных изменений, а также возможную функцию системной интеграции в обществе через воспроизводство институционально-регулятивных механизмов в определённом территориальном образовании.

Для дальнейшего изучения функций интеллигенции на современном этапе развития и определения её роли и значения в контексте проблемы целеполагания социокультурной модернизации регионов следует проработать ряд оставшихся за рамками исследования задач, в частности:

Учёт при анализе процесса целеобразования в системах управления, реализующих цели как средства побуждения к действию, внешних и внутренних по отношению к региональному сообществу факторов - требований, потребностей, мотивов, программ самого сообщества и его групп, а также исполнителей целей, включая аппарат властно-управленческой вертикали и интеллигенцию;

Разработка в рамках процесса «сборки» будущей российской интеллигенции как потенциала социокультурной модернизации регионов её потребностей и мотивов;

Оценка характера взаимодействия противоречий и коалиций не только между внешними и внутренними факторами, но и между ранее существующими и вновь возникающими в региональной целостности внутренними факторами возможно возникновение целей;

Правомерность в подобном постоянном самодвижении социума учёта потенциала молодого поколения, которое уже через 10-15 лет войдёт в государственные и кор- поративные структуры и будет отвечать за факторы его изменения.

\section{Список литературы}

Атлас модернизации России и ее регионов: социоэкономические и социокультурные тенденции и проблемы / Л. И. Беляева [и др.]; сост.-отв. ред. Н. И. Лапин. М.: Весь Мир, 2016. $360 \mathrm{c}$.

Волкова В. Н., Чабровский В. А. Цель: прогнозирование, анализ, структуризация. СПб.: Изд-во ИСЭП РАН, 1995. 114 с.

Касьянова А. Н. Средний город России: диагностика жизнедеятельности социума и социальное управление: автореф. дис. ... канд. социол. наук. Ростов-на-Дону, 2007. 26 с.

Лапин Н. И. Модернизация как глобальный вызов и стратегия повышения ее социокультурной эффективности в регионах России // Региональная социология: проблемы консолидации социального пространства России. М., 2015. C. 34-63.

Леньков Р. В. Социальное прогнозирование и проектирование. М.: ИНФРА-М, 2020. 189 c.

Леньков Р. В., Богданов В. С. Проблемы «сборки» будущей российской интеллигенции как потенциала социокультурной модернизации: социолого-управленческий дискурс // Научный результат. Социология и управление. 2019. Т. 5, № 4. C. 163-175. DOI: 10.18413/2408-9338-20195-4-0-15.

Россия: реформирование властноуправленческой вертикали в контексте проблем социокультурной модернизации регионов / А. В. Тихонов [и др.]; отв. ред. А. В. Тихонов. М.: ФНИСЦ РАН, 2017. 432 c.

Сагатовский В. Н. Русская идея: продолжим ли прерванный путь? // Серия: Россия накануне XXI века. СПб.: Петрополис, 1994. 217 с.

Тихонов А. В. Реформирование властноуправленческой вертикали как актуальная научно-исследовательская и практическая проблема // Социологическая наука и социальная практика. $2018 . \quad$ T. 6, № $4 . \quad$ C. 72-83. DOI: $10.19181 /$ snsp.2018.6.4.6085

Тихонов А. В., Богданов В. С. От «умного регулирования» к «умному управлению»: социальная проблема цифровизации обратных связей 
// Социологические исследования. 2020. № 1. C. 74-81. DOI: 10.31857/S013216250008325-0.

Тощенко Ж. Т. Общество травмы: между эволюцией и революцией (опыт теоретического и эмпирического анализа). М.: Издательство «Весь Мир», 2020. 352 с.

Щербина В. В., Попова Е. П. Вуз вне системы профессиональной подготовки специалистов как итог многолетних реформ российского высшего образования // Вестник Российского университета дружбы народов. Серия: Социоло$\begin{array}{lll}\text { гия. } 2020 . & \text { № } 20 \text { (3). } & \text { C. 622-635. }\end{array}$ DOI: 10.22363/2313-2272-2020-20-3-622-635.

Ackoff R. L., Emery F. E. On Purposeful Systems. Chicago: Aldine-Atherton, 1972.

Bourdieu P. Raisons pratiques: sur la théorie de l'action. Paris: Éd. du Seuil, 1994. 251 p.

Len'kov R. V. Provision of social and resource support to the policy of socio-cultural modernization of regions by the population with higher education // Economic and Social Changes: Facts, Trends, Forecast. 2018. Vol. 11. No. 6. Pp. 202-211. DOI: 10.15838 / esc.2018.6.60.12

Van Gigch J. P. Metadecisions: rehabilitation epistemology. Kluwer, 2003.

Von Bertalanffy L. General system theory. Foundations, development, applications. N.-Y., 1968.

\section{References}

Lapin, N. I. (2016), Atlas of modernization of Russia and its regions: socioeconomic and sociocultural trends and problems, Moscow, Russia. (In Russian)

Volkova, V. N. and Chabrovsky, V. A. (1995), Purpose: forecasting, analysis, structuring, St. Petersburg, Russia. (In Russian)

Kasyanova, A. N. (2007), "An average city of Russia: diagnostics of social life and social management", Abstract of Ph.D. dissertation, Rostovon-Don, Russia. (In Russian)

Lapin, N. I. (2015), "Modernization as a global challenge and a strategy for increasing its sociocultural efficiency in the regions of Russia", in Regional sociology: problems of consolidating the social space of Russia, Moscow, Russia, 34-63. (In Russian)
Len'kov, R. V. (2020), Social forecasting and design, Moscow, Russia. (In Russian)

Len'kov, R. V. and Bogdanov, V. S. (2019), "Problems of "assembling" the future Russian intelligentsia as the potential of socio-cultural modernization: sociological-managerial discourse", $R e$ search Result. Sociology and Management, 5 (4), 163-175. (In Russian)

Tikhonov, A. V. (2017), Russia: Reforming the power-management vertical in the context of problems of socio-cultural modernization of regions, Moscow, Russia. (In Russian)

Sagatovskiy, V. N. (1994), Russian Idea: Will We Continue the Interrupted Path?, St. Petersburg, Russia. (In Russian)

Tikhonov, A. V. (2018), "Reforming the power-management vertical as a topical research and practical problem", Sociological Science and Social Practice, 6 (4), 72-83. (In Russian)

Tikhonov, A. V. and Bogdanov, V. S. (2020), "From "smart regulation" to "smart management": the social problem of digitalization of feedbacks", Sotsiologicheskie Issledovaniia, (1), 74-81. (In Russian)

Toshchenko, Zh. T. (2020), Society of Trauma: Between Evolution and Revolution (Experiences from Theoretical and Empirical Analysis), Moscow, Russia. (In Russian)

Shcherbina, V. V. and Popova, E. P. (2020), "University outside the system of professional training of specialists as a result of many years of reforms in Russian higher education", Bulletin of the Peoples' Friendship University of Russia. Series: Sociology, (20), 622-635. (In Russian)

Ackoff, R. L. and Emery, F. E. (1972), On Purposeful Systems, Chicago, USA.

Bourdieu, P. (1994), Raisons pratiques: sur la théorie de l'action, Paris, France.

Len'kov, R. V. (2018), Provision of social and resource support to the policy of socio-cultural modernization of regions by the population with higher education, Economic and Social Changes: Facts, Trends, Forecast, 11, 6, 202-211.

Van Gigch, J. P. (2003), Metadecisions: rehabilitation epistemology, Kluwer.

Von Bertalanffy, L. (1968), General system theory. Foundations, development, applications, N.-Y., USA. 
Статья поступила в редакиию 01 ноября 2020 г. Поступила после доработки 30 ноября 2020 г. Принята к печати 05 декабря 2020 г.

Received 01 November 2020. Revised 30 November 2020. Accepted 05 December 2020.

Конфликты интересов: у автора нет конфликтов интересов для декларации.

Conflicts of Interest: the author has no conflict of interest to declare.

Леньков Роман Викторович, кандидат экономических наук, доцент, старший научный сотрудник Института социологии Федерального научно-исследовательского социологического центра Российской академии наук, членкорреспондент Академии военных наук Российской Федерации.

Roman V. Len'kov, Candidate of Economic Sciences, Assistant Professor, Senior Researcher, Institute of Sociology, Federal Center for Theoretical and Applied Sociology, Russian Academy of Sciences, Corresponding Member of the Academy of Military Sciences of the Russian Federation. 